\title{
Gill function and mucocyte distribution in Placopecten magellanicus and Mytilus edulis (Mollusca: Bivalvia): the role of mucus in particle transport
}

\author{
Peter G. Beninger ${ }^{1}$, Sylvie St-Jean ${ }^{1}$, Yves Poussart ${ }^{1}$, J. Evan Ward ${ }^{2}$ \\ ${ }^{1}$ Département de Biologie, Université de Moncton, Moncton, New Brunswick, Canada E1A 3E9 \\ ${ }^{2}$ Biology Department, University of New Brunswick (St. John), New Brunswick, Canada B2L 4L5
}

\begin{abstract}
In order to elucidate the role of mucus in particle transport on the gill in suspensionfeeding bivalves, the mucocyte distribution was examined on the frontal surfaces of 2 gill types known to differ in structure and function: the heterorhabdic plicate gill of Placopecten magellanicus (Pectinidae) and the homorhabdic gill of Mytilus edulis (Mytilidae). Microscopic counts of mucocyte abundance were performed both on whole mounts of gill segments and on histological sections stained with alcian blue and Periodic acid-Schiff (PAS). A very clear separation of mucocyte types was observed on the P. magellanicus gill: mixed-secretion mucopolysaccharide (MPS) mucocytes were found mainly in the principal filament troughs, while acic MPS mucocytes were found mainly on the crests of the ordinary filament plicae. This distribution corresponds to the functional specialization of these 2 sites as revealed by direct endoscopic observation: feeding (principal filament) and cleaning (ordinary filaments). A more uniform distribution and a broader range of MPS types was found for the $M$. edulis gill, corresponding to the absence of anatomical specialization for the separation of feeding and cleaning functions in this species. Although $M$. edulis gill functioning is characterized by the presence of a substantial mucus cord in the ventral groove, no mucocytes are located in this groove. Implications of these and further results are discussed in terms of theories of particle transport on different gill types.
\end{abstract}

\section{INTRODUCTION}

The role of mucus in bivalve suspension-feeding has been debated for over a century; theories of particle capture, transport, selection and ingestion rely heavily on assumptions concerning the sites and conditions of mucus secretion (e.g. MacGinitie 1941, Jørgensen 1966, 1990, Beninger et al. 1991, Beninger et al. 1992, Ward et al. 1993). Recent studies have confirmed the importance of mucus in particle ingestion, and suggested that mixedsecretion mucocytes are characteristic of surfaces involved in particle transport and ingestion (Beninger et al. 1991, Beninger \& Le Pennec 1993). It is therefore somewhat surprising that little is known concerning the locations of mucocytes or the types of mucus secretions on bivalve gills. Although Jørgensen (1990) assumed mucocytes on the bivalve gill to be 'isolated', qualitative data suggest that their distribution may be patterned and their numerical density quite high (Nelson 1960, Owen \& McCrae 1976, Ribelin \& Collier 1977). Furthermore, based on endoscopic observations of normal feeding where there are copious amounts of mucus on ciliated tracts, it is apparent that mucocyte number and density must be substantial in at least some structural elements (Ward et al. 1991, Beninger et al. 1992). These endoscopic observations also suggested that in the scallop Placopecten magellanicus there are 2 types of mucus of different viscosities: a low-viscosity secretion associated with dorsalward particle transport (feeding) and a highviscosity mucus associated with ventralward particle transport (cleaning). Although little is known about chemical composition and consequent properties of bivalve mucus, acidic mucopolysaccharides (MPS) of limpets are highly viscous (Grenon \& Walker 1978). 
Basic differences in gill type and structure have been shown to correspond to fundamental differences in the roles and trajectories of mucus on the gill (Ward et al. 1993). The distribution of mucocytes on the gill might thus also be expected to present patterns characteristic of these trajectories and roles. The present study seeks to address this question by examining the distribution and secretion types of mucus on the homorhabdic, filibranch gill of Mytilus edulis and the heterorhabdic, filibranch gill of Placopecten magellanicus.

\section{MATERIALS AND METHODS}

Specimen collection and preparation. A total of 12 adult Placopecten magellanicus measuring 9.0 to $12.1 \mathrm{~cm}$ (long axis parallel to shell hinge) were collected from Passamaquoddy Bay (Bay of Fundy, New Brunswick, Canada) and Bonne Bay (Newfoundland, Canada). A total of 10 adult Mytilus edulis measuring 5.8 to $6.2 \mathrm{~cm}$ shell length were collected from the intertidal zone at Chamcook Bay (Bay of Fundy). All specimens were transferred to the Université de Moncton, maintained at $5{ }^{\circ} \mathrm{C}$ and $33 \%$ in recirculating seawater, and fed once or twice weekly with spray-dried algae (Tetraselmis sp., Algal 161, Celsys, Inc.). The gills of both species were dissected and fixed for at least $48 \mathrm{~h}$ in aqueous Bouin's solution (Martoja \& Martoja 1967). which contains ethanol and picric acid and is therefore recommended for the histological detection of mucopolysaccharides (Cook 1990). After being very gently rinsed for at least $48 \mathrm{~h}$ in a full beaker to which a weak stream of cold running tap water was added, the gills were then microscopically dissected using microsurgical instruments, in order to separate the demibranchs and to remove the dorsal respiratory expansions of $P$. magellanicus (which interfered with observations in the dorsal regions of the gill).

Staining and mounting of whole gill segments. The dissected gill fragments were placed in labelled tissue processing capsules and stained according to the following optimum staining procedure determined from preliminary trials: $1 \%$ Alcian blue $8 \mathrm{GX}, \mathrm{pH} 2.5$ ( 5 min); distilled water rinse $(5 \mathrm{~min}) ; 1 \%$ periodic acid (3 $\mathrm{min})$; Schiff reagent $(30 \mathrm{~s}) ; 0.5 \%$ sodium metabisulfite $(3 \times 3 \mathrm{~min})$. Diastase and saliva-treated controls were run on histological sections in order to verify the specificity of the Periodic acid-Schiff (PAS) and alcian blue stains (Cook 1990). This protocol stains neutral mucopolysaccharides red, acidic mucopolysaccharides blue, and mixed mucopolysaccharides various colors in the mauve-violet range, depending on composition and fullness of the mucocyte. Interpretation of staining affinities was standardised
(Miller et al. 1979) using the Pantone Color ${ }^{\circledR}$ Formula Guide (Pantone, Inc., Moonachie, NJ, USA). After staining, the ascending and descending lamellae were carefully separated. Gill fragments were mounted on microscope slides in Farrants aqueous medium. In order to preserve the 3 -dimensional plical structure in Placopecten magellanicus, bits of broken glass coverslip were included prior to application of a whole coverslip.

Mucocyte counts. Placopecten magellanicus: The gill was divided into 4 counting zones along the length of the descending and ascending lamellae (Fig. 1). Within each zone, counts were performed for complete plicae (2 principal filaments and their ordinary filaments) between 2 rows of cilifers (Fig. 2). The distance between cilifers (= ciliated spurs, Beninger et al. 1988) was measured using a calibrated ocular micrometer, in order to standardize counts to $100 \mu \mathrm{m}$ of lamellar length. Mucocytes were viewed and counted using a compound microscope at a magnification of $100 \times$. For each principal filament, one count was performed in the dorso-ventral direction and one in the ventrodorsal direction. In cases where the 2 counts differed by more than 2 (with a total count 25 to 50 ) or 3 (with a total count $>50$ ), a third count was performed. The resulting means constituted individual data points. This procedure was repeated on 5 to 8 principal filaments of 3 different specimens, and the resulting means and standard deviations of the individual data points were calculated.

For the ordinary filament counts, target plicae containing 16 ordinary filaments were usually selected. The ordinary filaments were then divided into 5 groups: OF-1, OF-2, OF-4, OF-5 each containing 3 filaments and representing the sides of the plica, and OF-3 containing 4 filaments and representing the crest of the plica (Fig. 2). [On 4 occasions, plicae containing 15 ordinary filaments were selected. In such cases, one filament in either OF-1 or OF-5 was not counted (minimum mucocyte densities found in these filament groups).] Counts were performed as above for each filament in each group, and the means were calculated for each group. These means represented single data points. This procedure was repeated 5 to 8 times as above, and the resulting means and standard deviations were calculated. As these points represent mucocyte numbers per $100 \mu \mathrm{m}$ filament length, they are herein referred to as mucocyte densities.

Due to the curved shape, filament fusion and thickness of the gill in the dorsal and ventral ciliated tracts, reliable counts could not be made in these regions. However, qualitative observations were possible.

Mytilus edulis: The gills of 3 Mytilus edulis were divided into 4 zones as for Placopecten magellanicus. Counting was delimited dorso-ventrally by successive 
Fig. 1. Placopecten magellanicus. Schematic drawing of gill viewed along antero-posterior axis. Numbers designate counting zones, large arrows show particle movement on principal filaments (feeding), small arrows show particle movement on ordinary filament plicae (cleaning), and dashed line represents plane of section for Fig. 2. A: gill arch (ciliated tract); DB: dorsal bend (ciliated tract); DL: descending lamella; GA: gill axis; VB: ventral bend (ciliated tract); $\mathrm{x}$ : anteriorward direction of particles feeding) perpendicular to plane of drawing; o: anteriorward direction of cleaning) perpendicular to plane of drawing. The particle-mucus masses at the ventral bend are periodically dislodged by valve-clap movements in dorsal ciliated tracts $(A+D B$ : particles at ventral ciliated tract (VB:

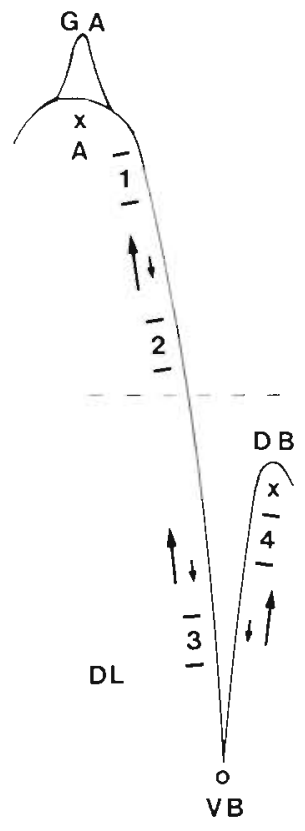

rows of interfilamentar junctions; as this species is homorhabdic, no antero-posterior anatomical marker was available. Counts were therefore performed on 5 groups of 10 consecutive filaments at equal intervals along the antero-posterior axis in 3 specimens using the method outlined for the ordinary filaments of $P$. magellanicus (Figs. $3 \& 4$ ). The results were standardized to $100 \mu \mathrm{m}$ filament length.

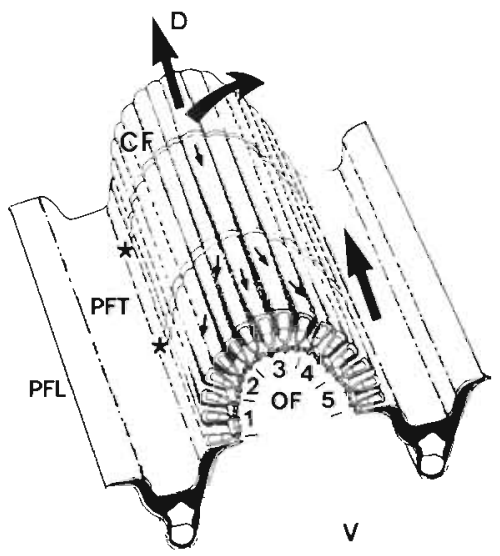

Fig. 2. Placopecten magellanicus. Schematic stereodiagram of descending lamella, showing filament groups used for counting. Large arrows indicate dominant currents and trajectories of particles destined for ingestion, small arrows indicate movement of particles destined for rejection beneath the dominant currents. Asterisks show dorso-ventral boundaries for a given count. CF: row of cilifers visible through ordinary filaments; D: dorsal; OF 1 to 5 : ordinary filament groups constituting a plica; PFL: principal filament lateral wall; PFT: principal filament trough; $V$ : ventral
Fig. 3. Mytilus edulis. Schematic drawing of gill viewed along antero-posterior axis. Numbers designate counting zones, arrows show direction of particle movement on gill, dashed line represents plane of section for Fig. 4. A: gill arch; AL: ascending lamella; DB: dorsal bend; DL: descending lamella; GA: gill axis; VB: ventral bend; $x$ : anteriorward direction of particle movement in ventral groove perpendicular to plane of drawing

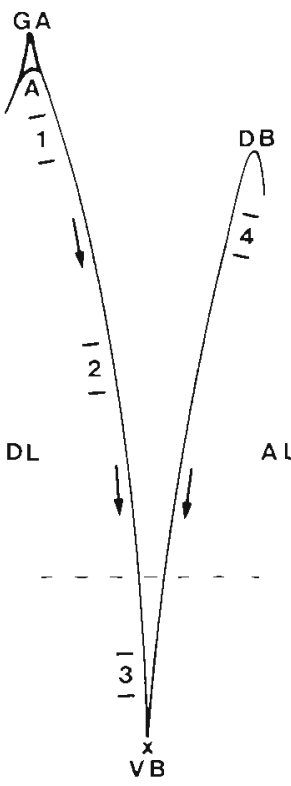

As for Placopecten magellanicus, technical difficulties hindered quantitative estimations of mucocyte density in the dorsal and ventral ciliated tracts. However, qualitative estimations were possible in the dorsal tracts; following separation by longitudinal dissection of the ascending and descending lamellae, such estimations were also possible in the ventral groove, albeit with a greater degree of uncertainty.

Histology - Mytilus edulis ventral groove. Due to both the importance of the ventral groove in the interpretation of feeding in mussels, and to the relative uncertainty of the whole mount results for this region, histological sections were performed. Gill tissue from 3 specimens was dehydrated in an ethanolHemoDe (Fisher Scientific) gradient, embedded in paraffin (Paraplast Plus, Fisher Scientific), serially sectioned in the dorso-ventral plane at $12 \mu \mathrm{m}$ (previously determined optimum section thickness for

Fig. 4. Mytilus edulis. Schematic stereodiagram of ventral region. Solid arrows show particle trajectories on frontal surface of gill filaments, open arrow shows oralward trajectory of mucusparticle cord. Asterisks indicate dorso-ventral boundaries for a given count. AL: ascending lamella; DL: descending lamella; G: position of putative subepithelial glands; IFJ: interfilamentar junction; ILJ: interlamellar junction; VB: ventral bend; VG: ventral groove

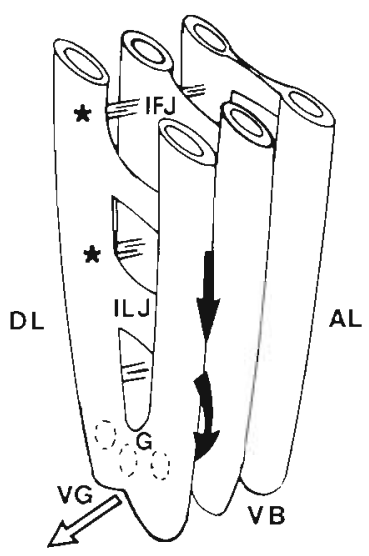


colour contrast), and rehydrated using a reverse ethanol-HemoDe gradient. The following staining protocol was adopted, based on preliminary trials: alcian blue $1 \% \mathrm{pH} 2.5$ (25 min); distilled water rinse (5 min); periodic acid $1 \%$ (5 min); Schiff reagent (12 min); sodium metabisulfite $0.5 \%$ (5 min); Hansen's trioxyhematein (30 s). Mucocytes were to be quantitatively assessed using stereological techniques (Beninger 1987).

Endoscopic observations. Extensive videotape recordings of gill function under a variety of particle concentrations were re-examined for both Placopecten magellanicus and Mytilus edulis (Beninger et al. 1992, Ward et al. 1993), in order to provide functional correlates to eventual distribution patterns of mucocytes.

\section{RESULTS}

The Pantone ${ }^{\circledR}$ colour-standardised results of the PAS-alcian blue staining technique on the mucocytes of each species are presented in Table 1. Whereas for Placopecten magellanicus the mucocytes could easily be divided into 2 categories - those containing only acid MPS (blue) and those containing a mixture of acid and neutral MPS (violet) - the range of resulting colours was much broader in Mytilus edulis. The $M$. edulis mucocytes were therefore divided into 2 categories: those containing dominantly neutral MPS, and those containing dominantly acidic MPS (Table 1).

\section{Placopecten magellanicus}

Qualitative observations revealed very few mucocytes in the gill arch, and a total absence of mucocytes in the ventral bend. The preparation and staining technique also revealed that ordinary filament plicae fuse as they approach the gill arch, and that their homologues on the opposite side of the arch are principal filaments, giving an alternating arrangement of plicae and principal filaments on either side of the gill axis.

\section{Principal filaments}

The principal filament troughs show a gradient of increasing mucocyte densities from the ventral to the dorsal regions (absence in the ventral bend and most of zone 3 , increasing densities in zones 2,1 \& 4). The vast majority ( 85 to $100 \%$ ) of these mucocytes produce mixed secretions (Fig. 5). Despite lower mucocyte densities than in the troughs, mixed-secretion mucocytes also dominate in the principal filament lateral walls, and display a similar ventro-dorsal gradient.

\section{Ordinary filaments}

In contrast to the principal filaments, the mucocytes on the frontal surface of ordinary filaments contain almost exclusively acid MPS secretions (Fig. 5). In each zone, the OF-3 group (plical crest) presents the greatest mean mucocyte densities (45 to 58 mucocytes per $100 \mu \mathrm{m}$ filament length); these densities decrease progressively in the OF groups on either side of the crest (Fig. 5).

\section{Mytilus edulis}

The distribution of mucocytes on the Mytilus edulis gill was much more uniform than that of Placopecten magellanicus. Total mean mucocyte densities ranged from 13 to 33 mucocytes per $100 \mu \mathrm{m}$, with a slight majority of acid-dominant MPS in zone 1 and a slight majority of neutral-dominant MPS in zone 4. As neither a priori nor a posteriori hypotheses could be advanced to justify statistical tests of significance, such tests were not performed. Zones 2 and 3 showed nearly equal densities of both mucocyte types (Fig. 6). There was no discernable pattern among the filament groups.

Both whole-mount staining of separated demibranchs and serial histological sections failed to reveal the presence of any mucocytes in the ventral groove of Mytilus edulis. However, subepithelial gland-like structures with PAS and alcian-blue staining affinities were observed dorsal to the ventral grooves (Fig. 4); similar, smaller structures were less frequently observed near the interfilamentar junctions.

Table 1. Mucocyte secretion type and corresponding Pantone ${ }^{\star}$ standard colors. MPS: mucopolysaccharide

\begin{tabular}{|lcc|}
\hline Species & Mucocyte secretion type & Standard colors \\
\hline Placopecten magellanicus & Mixed (acid + neutral) MPS & $275 \mathrm{c}$ \\
& Acid MPS & $2995 \mathrm{c}$ \\
Mytilus edulis & Neutral-dominant MPS & $227 \mathrm{c}, 233 \mathrm{c}, 234 \mathrm{c}$ \\
& Acid-dominant MPS & $267 \mathrm{c}, 266 \mathrm{c}, 2685 \mathrm{c}$ \\
\hline
\end{tabular}



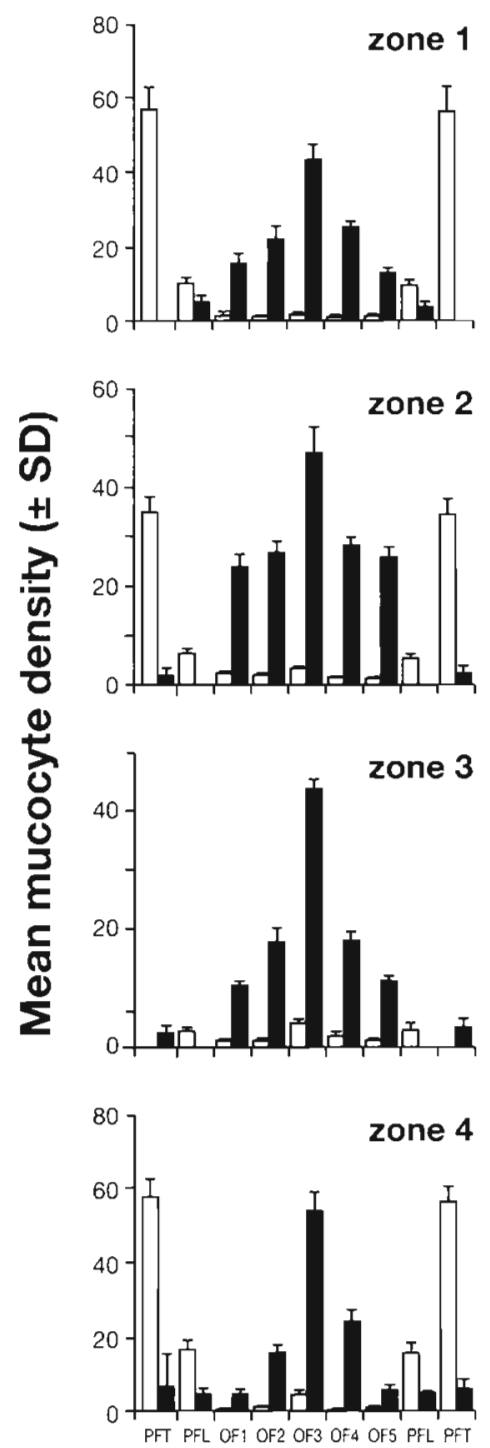

Filament group

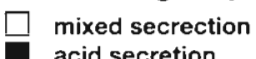

Fig. 5. Placopecten magellanicus. Mean mucocyte densities $( \pm S D)$ for each of the counting zones illustrated in Fig. 1 and each of the filament groups illustrated in Fig. 2. OF 1 to 5: ordinary filament groups 1 to 5; PFL: principal filament lateral wall; PFT: principal filament trough

\section{DISCUSSION}

Functional correlates to the observed mucocyte distributions require information on direct observations of normal (undisturbed) feeding at the gill of these 2 species. Such information is available in recent endoscopic studies of these species (Ward et al. 1991, 1993, Beninger et al. 1992). Re-examination of the videotapes of these experiments allowed functional inferences to be drawn from the mucocyte distribution data of the present study.
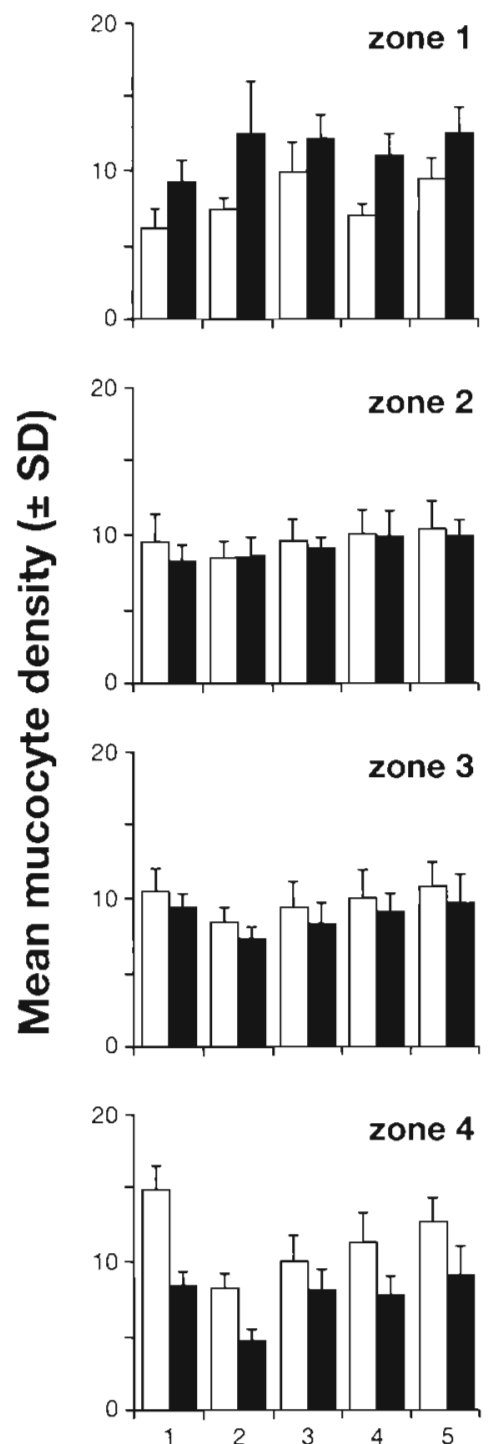

Filament group

neutral-dominant secrection acid-dominant secretion

Fig. 6. Mytilus edulis. Mean mucocyte densities ( \pm SD) of each counting zone illustrated in Fig. 4. Filament groups each consist of 10 consecutive filaments

\section{Placopecten magellanicus}

The qualitative observations by Owen \& McCrae (1976) suggested a distribution of mucocyte densities on the gill of the pectinid Chlamys varia similar to that reported here, although no distinction was made on the basis of mucocyte type. The striking pattern of the distribution of acid and mixed-secretion MPS mucocytes on the scallop gill observed in the present study underscores functional differences in the principal and ordinary filaments. The overwhelming dominance of mixed- 
secretion MPS in the troughs and lateral walls of the principal filaments agrees with previous observations that showed a dominance of mixed-secretion MPS mucocytes on surfaces involved in particle transport and handling in the oesophagus and peribuccal region (Beninger et al. 1990a, b, 1991). The observed increase in mucocyte densities from the ventral bend to the dorsal regions of the principal filaments suggests that for efficient particle transport in the scallop, mixed-secretion MPS must be added to particle streams prior to arrival in the dorsal ciliated tracts (gill arch and dorsal bend).

Previous endoscopic observations have suggested that the mucus accompanying particles from the principal filaments to the dorsal ciliated tracts was of reduced viscosity (Beninger et al. 1992). Evidence from studies on the pedal mucus in gastropods shows that weakly acidic MPS are characterized by reduced viscosity (Grenon \& Walker 1978). The mixedsecretion MPS of the principal filaments of Placopecten magellanicus would also be weakly acidic (combination of acid and neutral MPS).

Based on observed mucocyte densities, most of the mucus added to the particle stream in the principal filaments appears to originate in the floor of the trough, rather than in the lateral walls. This is not unexpected, as secretions from mucocytes on the lateral walls would be more easily lost from the principal filaments (given their proximity to the open side of the principal filaments).

In contrast to the principal filaments, the ordinary filaments present almost exclusively acid MPS in a very specific distribution: maximum densities on the crest filaments, and decreasing densities on either side. Previous endoscopic observations have shown that the ordinary filament plicae appear to function exclusively in the rejection of particles when the scallop's ingestive or handling capacity become saturated (Beninger et al. 1992). Particles appear to be embedded in clumps of highly viscous mucus on the plical crest and directed toward the ventral rejection tract (ventral bend). The distribution of acid MPS mucocytes corroborates these observations, and indicates the sites of mucus secretion. Contrary to the principal filaments, this distribution of mucocytes is uniform throughout the length of the OF; this may be linked to the observation that a given particle or particle clump may be ejected onto the plical crest several times as it moves ventrally in a looping fashion (Beninger et al. 1992). The quasi-exclusive presence of acid MPS mucocytes on the ordinary filament plicae underscores the functionally specific nature of these structures and the apparent specialization of acidic MPS in transport of particles for rejection. In addition to previous endoscopic observations (Beninger et al. 1992), evidence from the sole glands of 2 species of limpets indicate that acidic MPS are highly viscous (Grenon \& Walker 1978) and therefore mechanically stable. Such secretions would be well-suited for keeping particles close to the exposed rejecting epithelia. preventing re-suspension in pallial currents and thus increasing the cleaning efficiency.

The very low mucocyte densities observed both in the 2 dorsal ciliated tracts and the ventral bend, together with endoscopic observations of the presence of mucus in these tracts under various conditions (Beninger et al. 1992), indicate that these regions transport particles previously embedded in mucus. The results of the present study therefore show that most of the transport mucus is added to the particle stream within the principal filament, rather than from mucocytes in the dorsal ciliated tracts as originally postulated by Beninger et al. (1988). Together with previous data on the mode of particle ingestion (Beninger et al. 1991) and recent endoscopic studies (Beninger et al. 1992), these observations confirm that in Placopecten magellanicus mixed-secretion MPS accompanies captured particles from the principal filaments to the stomach.

From the foregoing it may be concluded that the Placopecten magellanicus gill exhibits a division of labour which is manifested both structurally (principal filaments: feeding; ordinary filaments: cleaning) and biochemically in the distribution and secretion types of mucocytes (mixed secretion: feeding, dominant on principal filaments; acid MPS: cleaning, restricted to ordinary filament plicae).

The serendipitous observation that principal filaments and ordinary filament plicae alternate on either side of the gill arch is an interesting anatomical observation in its own right, not previously observed using scanning electron microscopy (Beninger et al. 1988). In addition, such an anatomical disposition would result in a more uniform transfer of particles from the principal filaments to the gill arch tract.

\section{Mytilus edulis}

In contrast to Placopecten magellanicus, mecocyte numbers were generally lower and more uniform among the gill filaments of Mytilus edulis. The nearly equal mixture of neutral-dominant and acid-dominant MPS in zones 2 and 3 in $M$. edulis mucocytes suggests that the resultant mucus probably presents a viscosity intermediate to that of the mixed MPS secretion and acid MPS of $P$. magellanicus. This would correspond to the 'all purpose' nature of the mussel gill, where particles destined both for ingestion and rejection are transported to the ventral groove. The lack of clumping in the ventral mucus cord (Ward et al. 1993) also supports the hypothesis of an intermediate-viscosity mucus; the semi-enclosed space of the ventral groove probably 
shelters the cord from the currents of the pallial cavity, increasing transport efficiency. Binding particles in an intermediate-viscosity mucus would explain how they are transported close to the frontal epithelium without clumping in $M$. edulis, (Ward et al. 1993) whereas with the low-viscosity mucus of the $P$. magellanicus principal filaments, particles are transported hydrodynamically in semi-enclosed spaces (principal filaments). Although theoretical calculations show that hydro-mechanical shear forces may be sufficient to keep particles within the mussel frontal current without mucus (Sylvester \& Sleigh 1984), the observations of Ward et al. (1993) and those of the present study strongly support the idea that mucus is intimately involved in particle transport on the frontal surface under normal feeding conditions.

The observation of slightly unequal proportions of mucocytes in zone 1 (near the gill arch), and in zone 2 (dorsal bend) is enigmatic, since these tracts do not normally transport particles anteriorward. Furthermore, it is not certain that these apparent differences in mucocyte densities correspond to actual differences in mucocyte secretion or significant effect on particles, especially since all mucus secreted on this epithelium is combined in the vertical groove. Resolution of this question awaits further study.

The lack of mucocytes in the ventral groove of Mytilus edulis, as revealed by the whole mount staining and longitudinal histological sections, demonstrates that none of the mucus observed in the mucus cord (Foster-Smith 1978, Jørgensen 1981, 1990, Ward et al. 1993) is produced at this site. Previous endoscopic observations have shown that, contrary to the statements of Jørgensen (1981, 1990), all material intercepted by the mussel gill is transported ventrally and incorporated into a single mucus cord which travels anteriorward (Ward et al. 1993). The observations of the present study limit the possible origins of this mucus to 2 sites: the mucocytes of the frontal surface of the gill filaments and/or the gland structures observed within the filaments dorsal to the ventral grooves. Histochemical investigations now in progress indicate that these glands are similar to those found in the oesophagus (Beninger et al. 1991, Beninger \& Le Pennec 1993) and peribuccal organs of M. edulis (P. G. Beninger \& S. St-Jean unpubl.). It is interesting to note that the position of these subepithelial glands corresponds to the site where ventrally transported particles are shunted laterally between adjacent filaments immediately prior to reaching the ventral ciliated tract (Fig. 4).

\section{CONCLUSIONS}

When combined with endoscopic observations, the whole-mount staining technique has proven to be a use- ful tool for the elucidation of the role of mucus in bivalve suspension-feeding. The present study demonstrates fundamental differences in the mucocyte distribution on the gills of Placopecten magellanicus and Mytilus edulis. Together with previous endoscopic observations (Beninger et al. 1992, Ward et al. 1993), these differences are shown to correspond to and participate in specific modes of function. The complex heterorhabdic scallop gill, which lacks a ventral groove, displays a discrete division of tasks: the principal filaments transport particles dorsally in a low-viscosity mixed-secretion MPS for ingestion, while the ordinary filament plicae transport excess particles ventrally in high-viscosity acid MPS clumps which travel on the ciliated surface. The entire feeding pathway of $P$. magellanicus consists of semi-enclosed spaces (principal filaments, dorsal tracts, oral groove and peribuccal region, oesophagus), and this corresponds to the dominance of low-viscosity mixed-secretion MPS on all of these epithelia. However, the rejection pathway of the gills is totally open (ordinary filament plicae and ventral tract), and this corresponds to the prevalence of high-viscosity acid MPS mucocytes and secretions in these regions.

In the homorhabdic gill of Mytilus edulis all filaments are identical and all intercepted material is transported to the ventral groove in a homogeneous, intermediateviscosity mixture of MPS, such that there is no distinction between the tasks of ingestion (feeding) and rejection (cleaning). The ability of the ventral groove to open as observed in video endoscopic recordings may, however, constitute a means of ingestion volume regulation in this species. In addition, the mussel was observed to detach the dorsal bend from the mantle, thereby creating a shunt similar to that described for Placopecten magellanicus (Beninger et al. 1992). This would constitute a means of reducing particle clearance and hence of ingestion volume control.

Although a theoretical argument has been made that at the low Reynolds numbers under which particle-gill interactions have been assumed to take place, water currents can and do suffice to transport particles destined for ingestion (Jørgensen 1981, 1990, Jørgensen et al. 1984), the experimental data are consistent with the use of mucus at all times. Furthermore, recent research has demonstrated that many benthic suspensivores actually feed using structures operating at intermediate Reynold's numbers (Shimeta \& Jumars 1991); the exact situation in bivalves should thus be ascertained.

The question of the mechanism of particle selection remains unanswered, although the current and previous studies indicate that selection probably takes place in the presence of mucus of some type (see Beninger et al. 1992 for review). This question has proven intractable to date, and constitutes a challenging field for further research. 
Given the importance of mucus in the feeding process, detailed histochemical studies could allow the types of secretions at the different sites of the various bivalve gill types to be characterized. Data available for the composition of gill mucus in Crassostrea gigas show that over $97 \%$ is water, with the remaining $3 \%$ being composed of ash and organic matter (Bernard 1974). Data on energetic cost of mucus production by the gill is not available for any suspension-feeding mollusc; however, it should be noted that only a fraction of the mucus produced in feeding is 'lost' to the environment; an unknown amount is either re-absorbed by the peribuccal organs (Beninger et al. 1990a, b) or ingested along with the food particles. The greatest energetic cost would probably be incurred in the production of pseudofeces, when the bivalve uses mucus to remove excess particles from the gills, mantle, and peribuccal organs (Winter 1978). In the field, however, the production of pseudofeces would also be accompanied by gut fullness, and hence an adequate energy balance to support mucus production for rejection. The use of mucus is thus a simple, and probably energetically economical component of bivalve suspension-feeding.

Acknowledgements. The authors thank M. Leo Blanchard for his excellent photographic work. This study was funded by research grants from the Natural Sciences and Engineering Research Council (NSERC) and the Faculté d'études supérieures et de la recherche de l'Université de Moncton, and by a NSERC research studentship to S. St-J.

\section{LITERATURE CITED}

Beninger, P. G. (1987). A qualitative and quantitative study of the reproductive cycle of the giant scallop. Placopecten magellanicus, in the Bay of Fundy (New Brunswick, Canada). Can. J. Zool. 65: 495-498

Beninger, P. G., Auffret, M., Le Pennec, M. (1990a). The peribuccal organs of Placopecten magellanicus and Chlamys varia (Mollusca: Bivalvia): structure, ultrastructure and implications for nutrition. I. The labial palps. Mar. Biol. $107: 215-223$

Beninger, P. G., Le Pennec, M. (1993). A histochemical study of the bucco-oesophageal glands of the blue mussel Mytilus edulis L.: the importance of mucus in ingestion. $\mathrm{J}$. mar. biol. Ass. U.K. 73: 237-240

Beninger, P. G., M. Le Pennec, Auffret, M. (1990b). The peribuccal organs of Placopecten magellanicus and Chlamys varia (Mollusca: Bivalvia): structure, ultrastructure, and implications for nutrition. II. The lips. Mar. Biol. 107 $225-233$

Beninger, P. G., Le Pennec, M., Donval, A. (1991). Mode of particle ingestion in five species of suspension-feeding bivalve molluscs. Mar. Biol. 108: 255-261

Beninger, P. G., Le Pennec, M., Salaün, M. (1988). New observations of the gills of Placopecten magellanicus (Mollusca Bivalvia), and implications for nutrition. I. General anatomy and surface microanatomy. Mar. Biol. 98: 61-70

Beninger, P. G., Ward, J. E., MacDonald, B. A., Thompson, R. J (1992). Gill function and particle transport in Placopecten magellanicus (Mollusca: Bivalvia) as revealed using video endoscopy. Mar. Biol. 112: in press

Bernard, F. R. (1974). Particle sorting and labial palp function in the Pacific oyster Crassostrea gigas (Thunberg, 1795). Biol. Bull 146: 1-10

Cook, H. C. (1990). Carbohydrates. In: Theory and practice of histochemical techniques. Bancroft, J. D., Stevens, A. (eds.) Churchill Livingstone, London, p. 177-215

Foster-Smith, R. L. (1978). The function of the pallial organs of bivalves in controlling ingestion. J. mollusc. Stud. 44: $83-89$

Grenon, J. F., Walker, G. (1980). Biochemical and rheological properties of the pedal mucus of the limpet, Patella vulgata L. Comp. Biochem. Physiol. 66B: 451-458

Grenon, J. F, Walker, G. (1978). Histology and histochemistry of the pedal glandular system of two limpets, Patella vulgata and Acmea tessulata (Gastropoda: Prosobranchia). J. mar. biol. Ass. U.K. 58: 803-816

Jørgensen, C. B. (1966). The biology of suspension feeding. Pergamon Press, Oxford

Jørgensen, C. B. (1981). Feeding and cleaning mechanisms in the suspension feeding bivalve Mytilus edulis. Mar. Biol. 65: $159-163$

Jørgensen, C. B. (1990). Bivalve filter feeding: hydrodynamics, bioenergetics, physiology and ecology. Olsen \& Olsen Press, Fredensborg

Jørgensen, C. B., Kiørboe, T., Møhlenberg, F., Riisgard, H. U. (1984). Ciliary and mucus-net filter feeding, with special reference to fluid mechanical characteristics. Mar. Ecol. Prog. Ser. 15: 283-292

Kideys, A. E., Hartnoll, R. G. (1991). Energetics of mucus production in the common whelk Buccinum undatum $\mathrm{L}$. J. exp. mar. Biol. Ecol. 150: 91-105

MacGinitie, G. E. (1941). On the method of feeding in four Pelecypods. Biol. Bull. 80: 18-25

Martoja, R., Martoja, M. (1967). Initiation aux techniques de l'histologie animale. Masson, Paris

Miller, G. C., Allen, D. M., Costello, T. J. (1979). Maturation of the Calico scallop, Argopecten gibbus, determined by ovarian color changes. NE Gulf Sci. 3: 96-103

Nelson, T. C. (1960). The feeding mechanism of the oyster. II. On the gills and palps of Ostrea edulis, Crassostrea virginica, and C. angulata. J. Morphol. 107: 163-191

Owen, G. McCrae, J. M. (1976). Further studies on the latero-frontal tracts of bivalves. Proc. R. Soc. Ser. B 194: $527-544$

Ribelin, B. W., Collier, A. (1977). Studies on gill ciliation of the American oyster Crassostrea virginica (Gmelin). J. Morphol. 151: 439-450

Shimeta, J., Jumars, P. A. (1991). Physical mechanisms and rates of particle capture by suspension-feeders. Oceanogr mar. Biol. A. Rev. 29: 191-257

Sylvester, N. R., Sleigh, M. A. (1984). Hydrodynamic aspects of particle capture of Mytilus edulis. J. mar. biol. Ass. U.K. 64: $859-879$

Ward, J. E., Beninger, P. G., MacDonald, B. A., Thompson, R. J. (1991). A new technique for direct observations of feeding structures and mechanisms in bivalve molluscs using endoscopic examination and video image analysis. Mar. Biol. 11 1: 287-291

Ward, J. E., MacDonald, B. A., Thompson, R. D., Beninger, P. G. (1993). Mechanisms of suspension-feeding in bivalves: resolution of current controversies using endoscopy. Limnol. Oceanogr. 38: 265-272

Winter, J. E. (1978). A critical review on some aspects of filterfeeding in lamellibranchiate bivalves. Haliotis $7: 71-87$ 